\title{
Rektus Abdominis Kasında Endometriozis, Olgu Sunumu ve Literatürün Gözden Geçirilmesi
}

\author{
Rectus Abdominis Muscle Endometriosis, Case Report and Rewiew of the Literature
}

Semra Doğan' , Șafak Bulut², Salih Müjdat Balkan'1, ibrahim Tanzer Sancak³

TOBB ETÜ Hastanesi, Genel Cerrahi, Ankara, Türkiye.

2 TOBB ETÜ Hastanesi,Patoloji, Ankara, Türkiye.
3 TOBB ETÜ Hastanesi, Radyoloji, Ankara, Türkiye.

\section{Geliș tarihi : 30.04.2015 • Kabul tarihi: 01.06.2015}

İletișim

Op. Dr. Semra Doğan

Tel: 05326681258

E-posta: opdrsemradogan@yahoo.com

Özel TOBB ETÜ Hastanesi Genel Cerrahi Bölümü, Ankara, Türkiye

Sıklıkla pelviste yerleșen endometriosis daha az sıklıkta ekstrapelvik bölgelerde de görülebilir. Rektus abdominis
kasında izole endometriozis oldukça nadir görülen bir durumdur. Rektus abdominis kasında endometriosis tespit
edilen 36 yașında kadın hastanın olgu sunumunu yapmaktayız. Hasta, karnının sol tarafında, genç yașlardan beri var
olan ağrılı kitle șikayeti ile genel cerrahi polikliniğine kabul edildi. Fizik muayenede sol alt kadranda, yaklașık $4 \times 4 \mathrm{~cm}$
boyutlarında, ağrılı semi-solid kitle tespit edildi. Doppler ultrasonografide rektus abdominis kası arkası ve kısmen
içinde endometriozis saptandı. Tedavide total eksizyon ve PTF (Polytetrafluoroethylene) yama ile greftleme yapıldı.
Kitlenin patolojisi endometriozis olarak belirlendi.
Olgu sunumumuzda rektus abdominis kasında nadiren gelișmiș olan endometriozisi tartıștık.
Anahtar Sözcükler: Rektus Abdominis Kası, Ekstrape/vik Endometriozis
We present a case of endometriosis in rectus abdominis muscle diagnosed in a 36 year old woman. The patient was
admitted to the general surgery outpatient clinic with a painfull left abdominal mass since teen age. Physical exami-
nation showed $4 \times 4$ cm, painfull, semi-solid mass at the left lower abdominal quadrant. Doppler Ultrasonography
findings showed possible endometriosis behind and partially in rectus abdominis muscle. Total excision with poly-
tetrafluoroethylene patch grafting was performed to the mass. The pathology revealed endometriosis.
We discussed a rare case of endometriosis in rectus abdominis muscle in our case report.
Key Words: Rectus Abdominis Muscle, Extrape/vic Endometriosis

Endometrial stroma ve glandların uterus kavitesi dışında yerleşmesi 'endometriozis' olarak tanımlanır. Siklıkla pelviste yerleşen endometriosis daha az s1klıkta ekstrapelvik bölgelerde de görülebilir. Rektus abdominis kasinda izole endometriozis oldukça nadir görülen bir durumdur. Biz bu yazımız$\mathrm{da}$, puberte döneminden beri var olduğu ve eski phannenstiel insizyonundan uzakta tespit edildiği için, rektus abdominis kasinda spontan olarak geliştiğini düşündüğümüz endometriozis olgusunu sunmaktayı.

\section{Olgu}

Otuzaltı yaşında kadın hasta, karnının sol tarafinda ağrilı kitle şikayeti ile Genel Cerrahi polikliniğine başvurdu. Anamnezinde bu şikayetlerin ergenlik döneminde başladı̆̆ı, menstruasyon dönemlerinde ağrının arttığ1 ve kitlenin büyüdüğü öğrenildi. Hasta daha önce bu şikayetlerle hastaneye başvurduğunu ancak bir sonuca ulaşılamadığı belitti. Özgeçmişinde 10 yıl önce geçirilmiş bir sezeryan öyküsü mevcuttu. Fizik muayenede karin sol alt kadranda, rektus abdominis kası üzerinde, phannenstiel insizyonun yaklaşı $5-6 \mathrm{~cm}$ yukarısında, yaklaşı $4 \times 4 \mathrm{~cm}$ boyutlarında semi-solid bir kitle saptandi. Ultrasonografik incelemede; karın sol alt kadranda, rektus kası arka bölümünde ve kısmen içinde 40x35x15 mm boyutlarında, içinde kistik alanlar da izlenen iyi kanlanan, düşük ekolu solid görünümlü, öncelikli olarak endometriozisi düșündüren yap1 tespit edildi (Şekil 1-2). Renkli Doppler ultrasonografik de$\breve{g}$ erlendirmede, kitlenin inferior epigastrik arter yolu ile beslenmekte olduğu izlendi. Kitle total olarak eksize edildi ve PTF yama ile (Polytetrafluoroethylene patch) greftleme yapild. Histolojik incelemede; fibroadipöz doku içinde, yer yer çevre kas dokusuna uzanan, endometrial tipte kolumnar epitel ile döşeli kistik glandlar ve bunları çevreleyen endometrial stromanın olușturduğu kanamalı, iltihaplı odaklar tespit edildi (Şekil 3). 
Patolojik sonuç endometriosis olarak kesinleştirdi. Postoperatif dönemde herhangi bir komplikasyon gelişmeyen hasta taburcu edildi.

\section{Tartıșma}

Endometriozis; fonksiyonel endometrial dokunun uterus dışında bulunmasıdır ve doğurganlık çağ1 asemptomatik kadınlarda \%2-22 oranlarıda görülür (1). Endometriozis daha sik genital organlarda ve pelvik peritonda, nadir olarak da gastrointestinal sistem (GİS), büyük omentum, cerrahi skarlar, mezenter, böbrek, deri ve nazal kavitede görülür (2). GİS'de sıklığ1 \% 5.4-25 oranındadir (3). Rektosigmoid bileşkede görülme sıklığ1 \% 65 oranindadır ve bunu takiben de ileum ve apendikste görülür $(4,5)$. Ayrıca meme, akciğer, pankreas, karaciğer, üretra, vertebra, kemik, periferik sinirler ve santral sinir sisteminde de görüldüğü bildirilmiştir $(6,7)$. Rektus abdominis kasında endometriozis çok nadiren görülür ve ilk olarak 1993 'de Coley tarafindan rapor edilmiştir (8). Karın duvarı endometriozisi tüm eksternal endometriozis olgularının \%4'ünü olușturmaktadır. Çoğunlukla abdominal cerrahi özellikle jinekolojik ameliyatlar sonrasinda cilt ve cilt altı skar dokusunda, umbilikusta, nadir olarak da inguinal kanal ve rektus abdominis kasinda görülür $(1,9)$. Bununla birlikte cerrahi girișim olmadan gelişen rektus abdominis yerleşimli endometriozis olguları da bildirilmiştir (10-14).

Tablo 1'de literatürde tespit ettiğimiz, karın duvarında spontan gelişen beş endometriosis olgusu özetlenmiştir. Hastaların hiçbirinde jinekolojik ameliyat öyküsü yoktur. Yaş ortalamas1nin 35 olduğu izlenmektedir. Hastalarda sıklıkla ağrılı kitle şikayeti mevcuttur. Sadece bir hastada ağrisız kitle șikayeti bulunmaktadır. Karın duvarinda tespit edilen kitlenin boyutları $2 \times 2-7 \times 7 \mathrm{~cm}$ arasında değişmektedir. Hastalarda görüntüleme yöntemi olarak US (Ultrasonografi), BT (Bilgisayarlı Tomografi) ve MRG (Manyetik Rezonans Görüntüleme) kullanılmıştır. Tüm hastaların tedavisinde geniş eksiyon yapılmıştır. Bizim olgumuzda

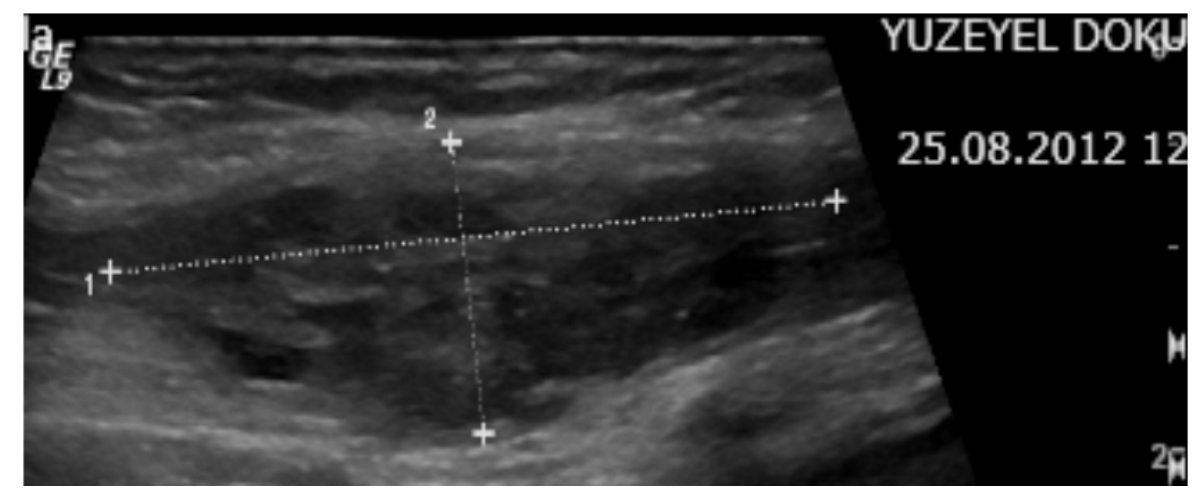

Şekil 1: Yüzeyel doku transdüseri ile elde edilen gri skala görüntüsü

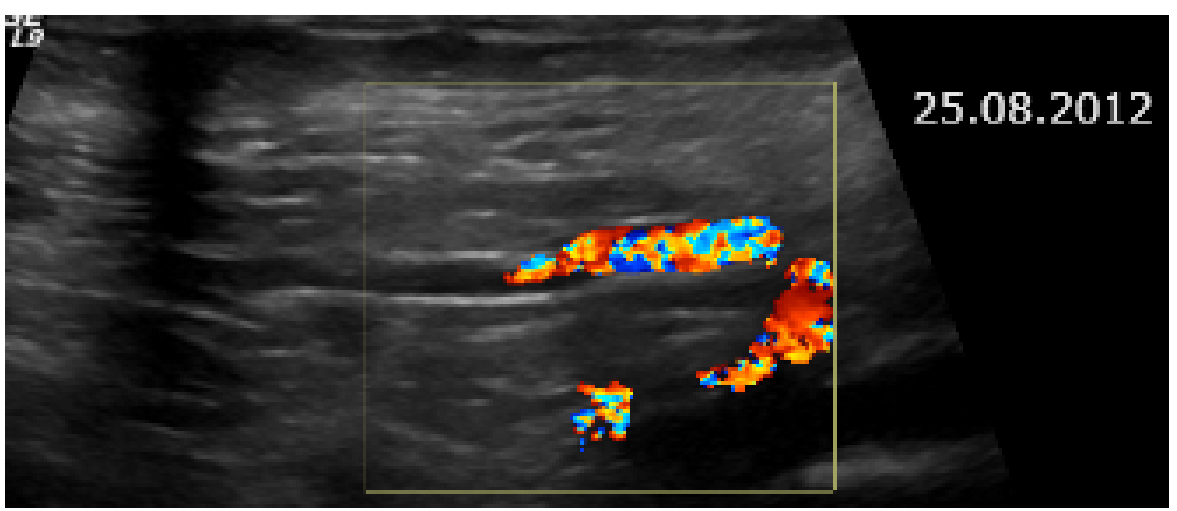

Şekil 2: Renkli Doppler US görüntüsü

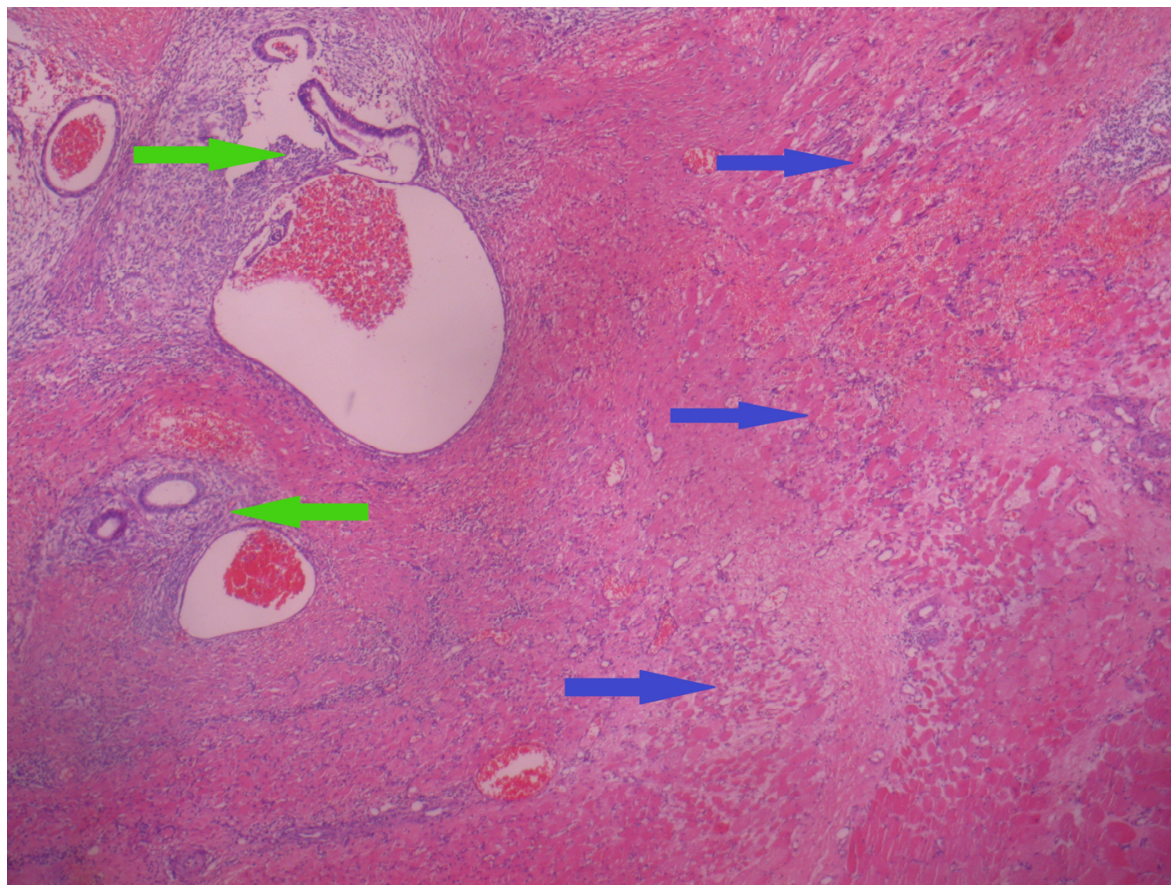

Şekil 3: Çizgili kas lifleri (mavi oklar) arasına uzanan fibröz doku içinde, endometrial tipte stromal hücrelerin çevrelediği kistik endometrial glandların oluşturduğu kanamalı odaklar (yeşil oklar) (HE, orijinal büyütme x100) 
Tablo 1: Rektus abdominis kasında endometriozis: literatürün gözden geçirilmesi

\begin{tabular}{llllllll}
\hline Yazar & Lit. & Hasta & $\begin{array}{l}\text { Yaș } \\
(\mathrm{yıl})\end{array}$ & $\begin{array}{l}\text { Semptom / } \\
\text { Bulgu }\end{array}$ & Boyut (cm) & Görüntüleme & Tedavi \\
\hline Idei & 10 & 1 & 28 & Ağrı-Kitle & $5 \times 3$ ve $2 \times 2$ & BT, MRG & Eksizyon \\
Tomas & 11 & 2 & 35 & Ağrı-Kitle & $4 \times 2$ & US,CT, MRG & Eksizyon \\
Esinler & 12 & 3 & 33 & Ağrı-Kitle & $4 \times 4$ & US & Eksizyon \\
Kocakușak & 13 & 4 & 37 & Kitle & $7 \times 7$ & US,BT & Eksizyon \\
Giannella & 14 & 5 & 32 & Ağrı-Kitle & $2 \times 2$ & BT, MRG & Eksizyon
\end{tabular}

US: Ultrasonografi, BT: Bilgisayarlı Tomografi, MRG: Manyetik Rezonans Görüntüleme

hastanın sezeryan öyküsü olmakla birlikte şikayetlerinin puberte döneminden beri olmasi ve lezyonun phannenstiel insizyonundan uzakta olması nedeniyle spontan gelişmiş bir endometriozis olarak düşünülebilir.

Endometriozisin sebebi kesin olarak bilinmemekle birlikte birkaç teori öne sürülmüştür. Sampson, endometriozisin primer etyoloji faktörünün retrograd menstruasyon olduğu teorisini savunmaktadir (15). Bu teori menstruasyon boyunca yaşama yeteneğindeki endometrial hücrelerin fallop tüplerinden reflü olmasıyla (retrograd menstürasyon) pelvis içine dökülmesi ve çevre dokulara implante olması esasına dayanır. Bunun dışında intraoperatif implantasyon, vaskülerlenfatik yayılma ve metasplastik teoriler de öne sürülen diğer teorilerdir (16). Vasküler yayılım teorisine göre; endometrial hücreler kan damarları veya lenfatik sistemle ekstragenital bölgelere ulaşarak, endometriotik odakların oluşmasına neden olmaktadir. Bizim olgumuzda gelişen endometriozis; hastanın her ne kadar sezeryan öyküsü olsa da, bu şikayetlerin puberte döneminden beri olması ve kitlenin yerleşim yerinin insizyon skarindan uzakta olası nedeniyle vasküler-lenfatik yayılım teorisi ile açıklanabilir.

Cilt ve cilt altı endometriozis olgularında lezyon yerinde menstruasyon esnasında lokalize ağrı, hassasiyet ve renk değişiklikleri görülebilir. Yüzeyel lezyonlarda kanama ve ülserasyon belirginken daha derin yerleşimli lezyonlarda renk değişimi görülmeyebilir (16). Rektus abdominis kasinda yerleşmiş endometriozis olguları asemptomatik olabileceği gibi çok ağr1lı hassas bir kitle olarak da görülebilir. Bi- zim olgumuzda karın duvarında ele gelen ve menstruasyon dönemlerinde büyüyen ağr1lı bir kitle mevcuttu. Ciltte herhangi bir renk değişikliği yoktu.

Karın ön duvarında görülen endometriozis olgularının birçoğunda kitle rektus kası yanında fasya, subkutan doku gibi diğer karın katlarını da içerebilir (17). Bizim olgumuzda fibroadipöz doku içerisinde rektus kasına uzanan endometriozis odakları tespit edilmiştir.

Endometriozis ayıric1 tanisinda apse, lipom, hematom, sebase kist, desmoid tümör, primer veya metastatik kanserler düşünülmelidir (18).

Görüntüleme yöntemleriyle endometriozis tanısı koymak güçtür. Tanı yöntemi olarak Ultrasonografi (US), Bilgisayarlı Tomografi (BT), Manyetik Rezonans Görüntüleme (MRG) gibi yöntemler kullanılabilir. Endometriozisin ultrasonografik olarak spesifik bir bulgusu olmasa da klinik öykü ve ultrasonografi eşliğinde yapılan iğne asprasyon biyopsileri tanıda yardımcı olabilir (19). Kitle içerisindeki hemoraji odaklarını göstermesi nedeniyle endometriozis tanısında MRG'nin üstün olduğunu bildiren yayınlar (20) olsa da yapılan bir çalışmada endometriozis tanisinda MRG'nin sensitivitesi $\% 64$, spesivitesi $\% 60$ ve doğruluk derecesi $\% 63$ olarak bulunmuștur (21). Ultranosografi; endometriozis tanısında birinci basamak tanı yöntemidir. Klasik adneksiyel endometriozis olgularında bulgular; düșük ekolu, nisbeten düzgün konturlu, yuvarlak şekilli, ince duvarlı, kistik kitleler şeklindedir. Klasik görünüm dişında kalan, yara yeri yerleşimli endometriozis olgularında bulgular ise daha çok solid görünümün hakim olduğu, kistik kompenentin nadiren eşlik ettiği, homojen olmayan hipoekoik yapıll, ince ekojenik çekintilerin ve fibrotik komponentlerin eşlik ettiği, kaba spiküler uzanıml, düzensiz kenarları olan ve renkli Doppler US ile akımın gösterilebildiği yapılardır (22). Ayrıca; aylık periyodların indüklediği reaksiyonel çevresel tabakanın oluşturduğu ekojenik kenarlar da US bulgularına eklenebilir. Yine olgularda $30 \mathrm{~mm}$ ve üzerinde çaplarda kistik alanların daha fazla eşlik ettiği ve klasik yuvarlak şeklin kaybolduğu, çok sayıda damar pedikülünün yapılanmaya dahil olduğu bildirilmektedir. Bu fazla damarlanmanın getirdiği kanama, rezorbsiyon ve inflamasyonun doğal sonucu ise heterojen yapilanmadir. Bizim olgumuzda yapilan Doppler Ultrasonografi'de; hem klasik adneksiyel hem de yara yeri yerleşimli endometriozis için yukarıda tanımlanan US görünümlerinin birçok formu birliktelik göstermektedir.

Karın duvarı endometriozisin tedavisi kitlenin total olarak eksizyonudur. Koger ve arkadaşları geniş eksziyondan sonra rekürrens oranlarının düşük olduğunu bildirmiştir (9). Bazen kitlenin adezyonuna bağlı olarak fasia rezeksiyonu ve greftleme de gerekebilir (18). Bizim olgumuzda da total eksizyon ve geftleme işlemi yapılmıştır.

Sonuç olarak üreme çağındaki kadınlarda, özellikle abdominal veya pelvik cerrahi geçirmiş olanlarda, karın duvarında ele gelen ve özellikle mensturasyonla ağrilı olan kitlenin ayırıcı tanisinda endometriozis düşünülmelidir. Görüntüleme yöntemleri her zaman tanı koydurucu olmayabilir. Kesin tanı kitlenin histopatolojik incelenmesiyle konulur. Halen en etkili tedavi yöntemi kitlenin total olarak çıarılmasıdır. 


\section{KAYNAKLAR}

1. Blanco RG, Lanco RG, Parithivel VS, et al. Abdominal wall endometrioma. Am J Surg 2003; 185:596-598.

2. Bergvist A. Extragenital endometriosis: a review. Eur J Surg 1992; 158:7-12.

3. Weed JC, Ray JE. Endometriosis of the bowel. Obstet Gynecol 1987; 69:727-730.

4. Remorgida V, Ferrero S, Fulchery E, Ragni N, Martin DC. Bowel endometriosis: presentation, diagnosis and treatment. Obst Gynecol Surv 2007; 62:461-470.

5. Dogan S, Bulut AS, Karamursel BS. Akut Apandisitin Nadir Ayırıc1 tanıs: Appendiks Endometriozisi. UCD 2012; 28:159-161.

6. Gabriel A, Shores JT, Poblete M, Victorio A, Gupta S. Abdominal wall endometrioma. Ann Plast Surg 2007; 58:691-693.

7. Sağlam M, Balkan A, Taşar M, Balkan M, Bozlar U, Kocaoğlu M. Pulmonary endometriosis: Diagnosis with computed tomography and high resolution computed tomography. European Journal of Radiology Extra 2005; 56:25-28.

8. Coley BD, Casola G. İncisional endometrioma involving the rectus abdominis muscle and subcutaneus tissues: CT apperance AJR 1993;160:549-550.
9. Koger KE, Shatney $\mathrm{CH}$, Hodge $\mathrm{K}$ et al. Surgical scar endometrioma. Surg Gynecol Obstetr 1993;177:243-246.

10. Ideyi SC, Schein M, Gertz PH. Spontaneus endometriosis of the abdominal wall. Dig Surg 2003; 20:246-248.

11. Tomas E, Martin A, Garfia C et al. Abdominal wall endometriosis in absence of previus surgery. J Ultrasound Med 1999;18:373-374

12. Esinler I, Güven S, Akyol D et al. Abdominal wall endometriosis without previus surgery. J Obstet Gynaecol 2004;24: 931

13. Kocakusak A, Arpinar E, Arikan S et al. Abdominal wall endometriosis: A diagnostic dilemma for surgeons. Med Princ Pract 2005;14:434-437

14. Giannella L, Marca AL, Ternelli G et al. Rectus abdominis muscle endometriosis: Case report and rewiew of the literature J.Obstet Gynaecol Res 2010;36:902-906.

15. Sampson JA. Metastatic or embolic endometriosis, due to menstrual dissemination of endometrial tissue into the venous circulation. Am J Pathol 1927;93-110.
16. Ferrari BT, Shollenbarger DR. Abdominal wall endometriosis following hypertonic saline abortion. JAMA 1977; 238:56-57.

17. Khaleghian R. Abdominal wall endometriosis. Sonographic diagnosis. Australas Radiol 1995;39:166-167.

18. Dwivedi AJ, Agraval SN, Silva YJ. Abdominal wall endometriomas. Digestive Dis Sci 2002; 47:456-461.

19. Wolf C. Sonografic features of abdominal wall endometriosis. AJR 1997; 169:916.

20. Balleyguier C, Chapron C, Chopin N, Helenon O, Menu Y. Abdominal wall and surgical scar endometriosis result of magnetic resonance imaging. Gynecol obstet Invest 2003; 55:220-224.

21. Arrive L, Hricac H, Martin MC. Pelvic Endometriosis: MR Imaging. Radiology 1989;171:687-692.

22. Francica G. Reliable clinical and sonografic findings in the diagnosis of abdominal wall endometriosis near cesarean section scar. World J Radiol. 2012; 4:135-140. 